\title{
Report of the International Conference in Sport Science "ICSS 2019" of the Sports University of Tirana
}

\author{
Juel Jarani ${ }^{1}$ \\ 'Sport University of Tirana, Tirana, Albania
}

\begin{abstract}
The article is providing highlights of the Report of the International Conference in Sport Science "ICSS 2019", hosted by the Sports University of Tirana. The event was held on December 6-7, 2019 in Tirana, Albania. The Conference provided space for presentation research papers and related discussion, as well as for poster sessions. The Conference was officially opened in the large conference hall of the Sports University of Tirana by prof. Agron Cuka, PhD, Rector of the Sports University of Tirana and chairman of the Conference scientific committee. This prestigious event gathered 264 authors and 84 participants, coming from 7 countries.
\end{abstract}

Keywords: Scientific Conference, Sport Science, Sports University, Tirana

\section{Introduction}

The greatest international event from the area of sports sciences was successfully held in Tirana, Albania this year. Namely, it was known that a severe earthquake struck Albania a few days ago. Therefore, the organizing committee thanked the guests who still came in large numbers and supported them in these difficult moments.

The International Scientific Conference "ICSS 2019" was hosted by the Sports University of Tirana on December 6-7, 2019 in Tirana. It has been considered as very important scientific events related to the sports sciences in the region, which helps connectivity and scientific collaboration which is necessary if the countries of the Western Balkans want to follow world trends and continuous progress in this area. The conference that was firmly confirmed the quality as it hosted 264 authors and 84 participants from 7 countries.
This year's conference is the third in a row organized by the Sports University of Tirana $(2014,2017,2019)$. The quality and number of participants has exceeded the previous two, and the organizers hope that the quality will grow from year to year. The conference provided the platform for researchers and experts who had an opportunity for networking through discussions and exchange on the international level. This event gave an opportunity for experts not only to network, but also to share ideas and present their research to a worldwide community.

In the words of the conference president prof. Agron Cuka, $\mathrm{PhD}$, the physical activity has a very important role in improving people's life and for that reason, the scientific research is growing up rapidly and our university is giving its contribution. It is very important that in these activities we have partners in Balkan and Europe and we are trying to improve our cooperation to ameliorate in every field of our activity.

\section{Correspondence:}

Montenegro J.Jarani

Sport Sport University of Tirana, Rruga Muhamet Gjollesha, 1001 Tiranë, Albania

E-Mail: jjarani@ust.edu.al 


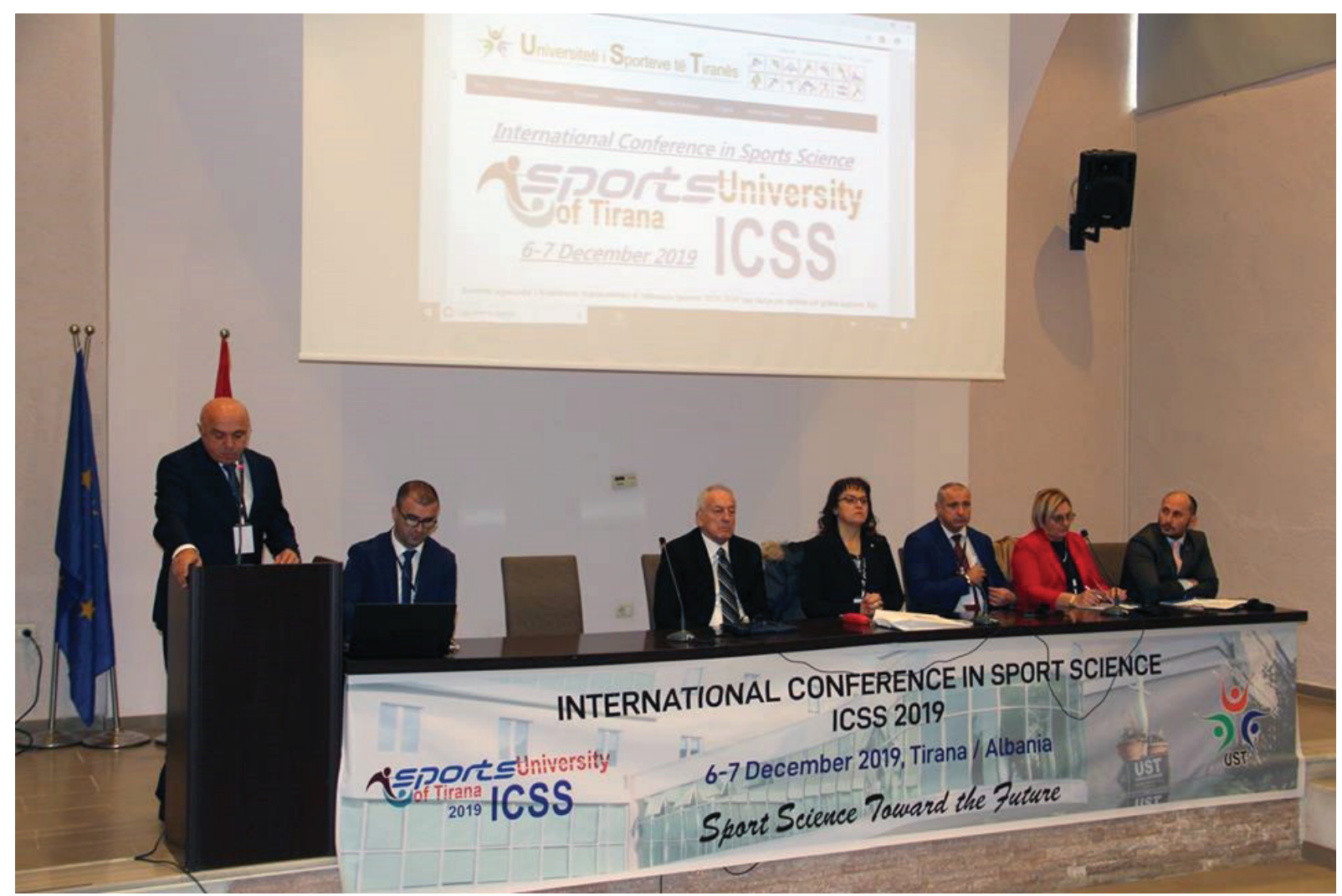

Picture 1. Opening ceremony

The theme of this Conference "Sports Science Toward the Future" and its content shows our intention to promote quality physical education (including health, movement related physical activity, recreation etc.) and sport especially in the schools and other learning institutions, by emphasizing the importance of daily physical exercise and facilitating better method- ologies for being healthy through taking active lifestyle for all age groups regardless any form of disabilities. This conference provides a show case for developments in the fields of physical activity and sport and we can learn from each other by sharing experiences and lessons, said Prof. Agron Cuka, PhD, conference president.

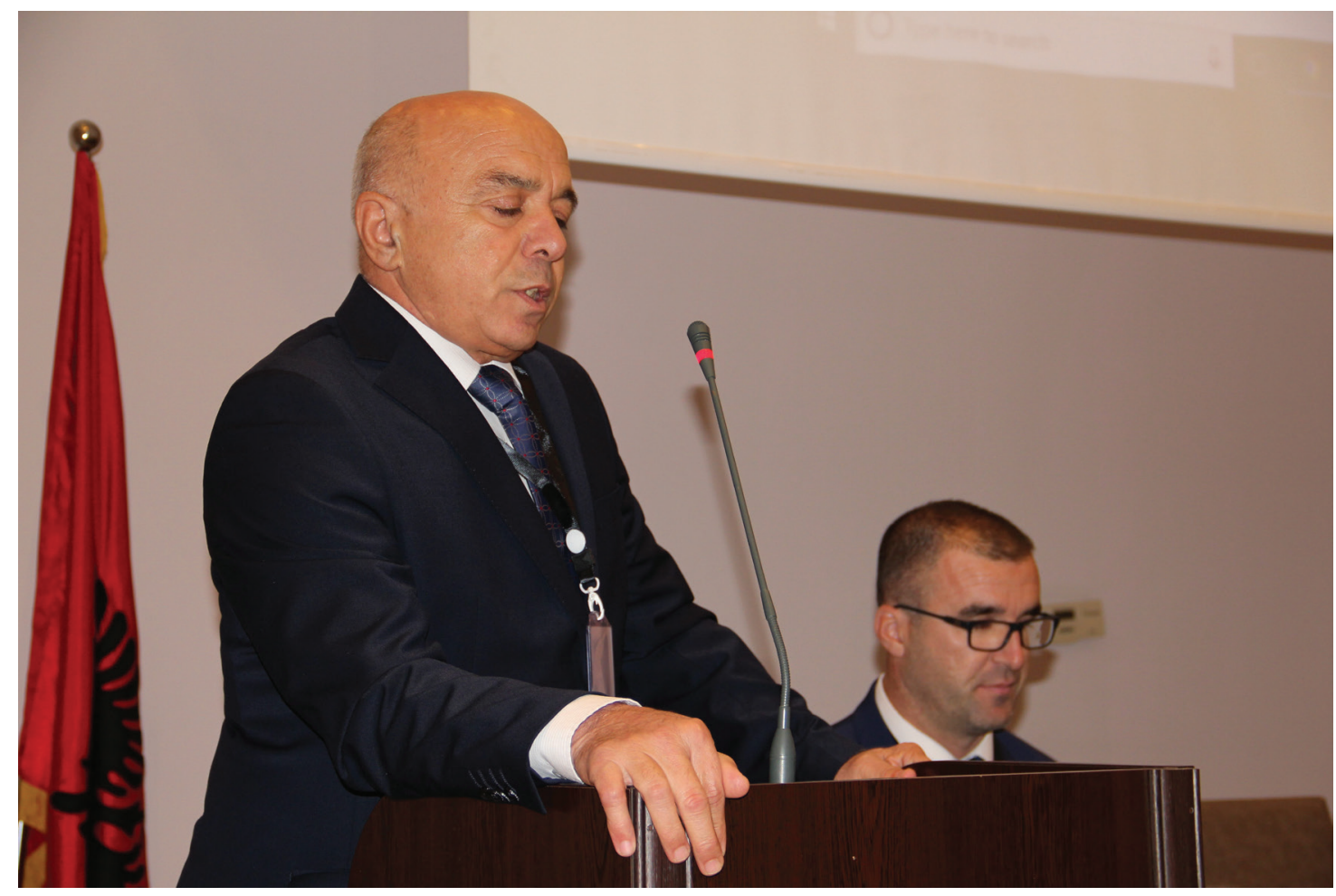

Picture 2. Conference president PROF. AGRON CUKA, PHD 
After the conference president, the meeting was welcomed by prof. Ramona Lile, PhD, Rector of the University of Arad "Aurel Vlaicu", prof. Zsombor Lacza, PhD, vice-rector of the University of Physical Education, Budapest, prof. Tomislav Kris- ticevic, $\mathrm{PhD}$, dean of the Faculty of Kinesiology in Zagreb, prof. Ivanka Gajic, PhD, dean of the Faculty of Sports in Belgrade and prof. Ibrahim Kubilay, PhD, Erasmus+ Coordinator of Suleiman Demirel University of Isparta.

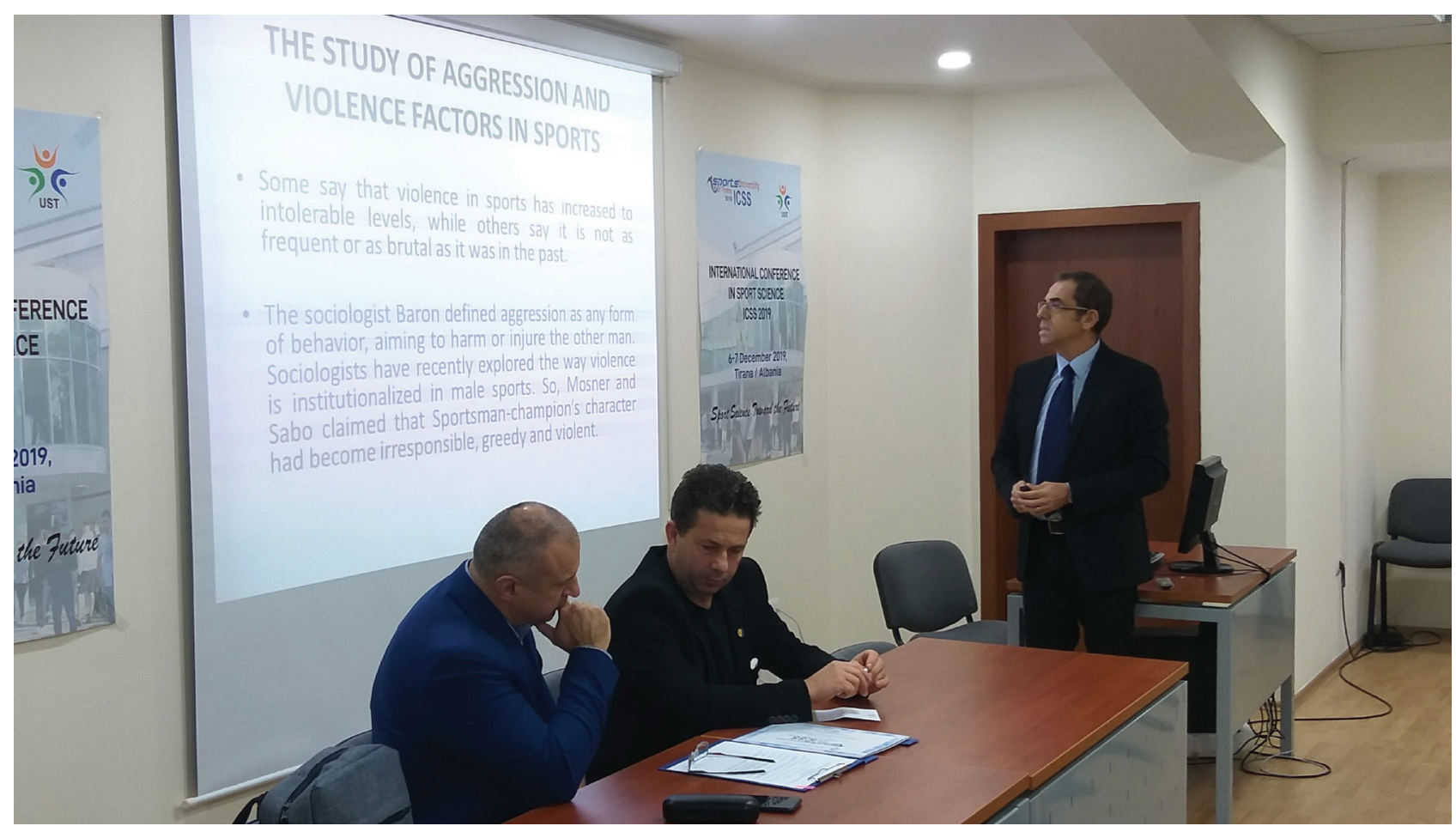

Picture 3. Session 4, Social Sciences-Legislation and Sport Management

The ceremony was followed by a plenary session in which they lectured, prof. Zsombor Lacza, PhD, from Hungary, assist. prof. Bojan Masanovic, $\mathrm{PhD}$, from Montenegro, prof. Tomislav Krističević, $\mathrm{PhD}$, from Croatia, prof. Liviu Andreu, $\mathrm{PhD}$, from Romania, prof. Uros Mitrovic, $\mathrm{PhD}$, from Belgrade and prof. Fadil Mamuti from Macedonia.

The program continued with an oral session focusing on Physical Education, Training and Performance, followed by a poster session that ended today's program.

On the second day of the conference there are three sessions on the program, the first on the topic of Social Sciences and Sports Management and the second and the third on the topic of Physical Activity and Health.

This was followed by the closing ceremony of the conference in the afternoon and another address by the rector, Prof. Agron
Cuka, PhD, who thanked the guests, wished them happy holidays, and invited them to be in the same place next year.

\section{Acknowledgements}

There are no acknowledgements.

\section{Conflict of Interest}

The authors declare that there are no conflicts of interest.

Received: 7 December 2019 | Accepted: 23 December 2019 | Published: 10 January 2020

\section{References}

Sports University of Tirana. (2019). Book of Abstract of the International Conference in Sport Science "ICSS 2019". Tirana: Sports University of Tirana. International Conference in Sports Science. (2019). Programme ICSS 2019. Available from Sports University of Tirana website: http://ust.edu.al/ wp-content/uploads/2019/12/PROGRAM-ICSS-2019.pdf. 